\title{
DIVERGÊNCIA GENÉTICA EM HÍBRIDOS DE SORGO CULTIVADOS SOB DIFERENTES NÍVEIS DE FÓSFORO, EM SOLUÇÃO NUTRITIVA
}

\author{
FILIPE LUIS SÁVIO ${ }^{1}$, PRISCILA NEVES FARIA ${ }^{1}$, WELISON ANDRADE PEREIRA ${ }^{1}$, \\ ALUÍZIO BORÉM DE OLIVEIRA ${ }^{1}$, FLÁVIO DESSAUNE TARDIN ${ }^{2}$, JOSÉ AVELINO \\ SANTOS RODRIGUES ${ }^{2}$ e ROBERT EUGENE SCHAFFERT ${ }^{2}$
}

\begin{abstract}
${ }^{I}$ Universidade Federal de Viçosa, Viçosa, MG, CEP 36570-000. Graduando em Agronomia e-mail:filipe.savio@ufv.br; Mestranda em Estatística Aplicada eBiometria,e-mail:prineves@ vicosa.ufv.br; Doutorando em Genética e Melhoramento e-mail:welisonaper@yahoo.com.br; ProfessorDoutor,e-mail: borem@ufv.br

${ }^{2}$ Empresa Brasileira de Pesquisa Agropecuária, Centro Nacional de Pesquisa Milho e Sorgo, Sete Lagoas, MG, CEP: 35701-970. Pesquisador A, e-mail: tardin@cnpms.embrapa.br; PesquisadorA,e-mail: avelino@cnpms.embrapa.br; PesquisadorA,e-mail: schaffer@cnpms. embrapa.br
\end{abstract}

$\overline{\text { Revista Brasileira de Milho e Sorgo, v.7, n.3, p. 305-321, } 2008}$

RESUMO - Os objetivos deste trabalho consistiram em identificar a presença de diversidade genética entre acessos de sorgo, em diferentes condições de disponibilidade de $\mathrm{P}$, em solução nutritiva, e determinar quais as características que mais contribuíram para a discriminação dessa divergência. $\mathrm{O}$ experimento foi conduzido em casa-devegetação, num arranjo fatorial $9 \times 4$, sendo nove híbridos de sorgo e quatro doses de $\mathrm{P}$ (3, 32, 97 e $129 \mu \mathrm{M}$ de P.L -1 $^{-1}$ de solução nutritiva), sob delineamento em blocos ao acaso, com três repetições. Os dados foram submetidos à análise de variância e, posteriormente, ao estudo de dissimilaridade genética, utilizando a matriz de distância generalizada de Mahalanobis e a contribuição relativa das características para a divergência, pelo método de Singh (1981). Concluiu-se que a dose de $3 \mu \mathrm{M}$ de P.L $\mathrm{L}^{-1}$ de solução apresentou valores discrepantes dos demais, sendo desconsiderados seu valores para análise de variância conjunta. Diferenças significativas para todas as características avaliadas foram observadas entre os híbridos, nas doses de $\mathrm{P}$ analisadas (32, 97 e $129 \mu \mathrm{M}$ de P.L. ${ }^{-1}$ de solução nutritiva). A concentração de $97 \mu \mathrm{M}$ de P.L. $L^{-1}$ gerou o maior número de grupos de genótipos. Entretanto, variabilidade genética foi observada também nas demais doses de P. Sob as concentrações de P avaliadas, verificou-se que a característica massa seca total foi a que mais contribuiu para a expressão da dissimilaridade genética entre os híbridos. O híbrido experimental 0735019 apresentou eficiência e responsividade a utilização de 
$\mathrm{P}$, demonstrando os maiores valores para as características avaliadas nos diferentes níveis de P estudados.

Palavras-chave: Sorghum bicolor, dissimilaridade genética, análise multivariada, doses de P.

\title{
GENETIC DIVERGENCE AMONG SORGHUM HYBRIDS CULTIVATED IN NUTRITIVE SOLUTION WITH DIFFERENT PHOSPHORUS LEVELS.
}

\begin{abstract}
The objectives of this study were to identify genetic diversity among accessions of sorghum in different conditions of $\mathrm{P}$ availability in nutrient solution and to determine the characteristics that contributed in discriminating this divergence. The experiment was conducted under greenhouse conditions using a 9x4 factorial arrangement, with nine sorghum hybrids and four doses of $\mathrm{P}(3,32,97$ and $129 \mathrm{mM} \mathrm{P}$ per liter of nutrient solution), in a randomized blocks design with three replications. Data were submitted to analysis of variance and genetic dissimilarity was determined using the Mahalanobis generalized distance matrix and relative contribution of traits for the genetic divergence using the Singh (1981) method. As discrepant values were obtained using the nutrient solution containing $3 \mathrm{mM}$ of P.L.-1, these data were excluded from the combined analysis of variance. Significant differences among hybrids were observed

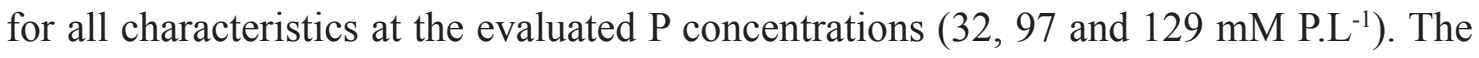
concentration of $97 \mathrm{mM}$ of P.L $\mathrm{L}^{-1}$ generated the largest number of groups of genotypes, however, genetic variability was also observed for the other P concentrations. Total dry mass presented the highest contribution to the expression of genetic dissimilarity between the hybrids, at the evaluated P concentrations. The experimental hybrid 0735019 demonstrated both efficiency and responsiveness to $\mathrm{P}$, showing the highest values for the characteristics evaluated at the different levels of $\mathrm{P}$.
\end{abstract}

Key words: Sorghum bicolor, genetic divergence, multivariate analysis, P levels.

Existem várias evidências de 2007; Boutraa, 2009) e quanto ao controle variabilidade dentro e entre espécies quanto ao uso, acúmulo e eficiência no uso de fósforo (Alves, 2002; Brasil et al., 2007; Cantão, Essas variações genotípicas ajudam a explicar 
a adaptação de espécies e cultivares às diversas condições de estresse ambiental e formam a base genética para programas de melhoramento (Machado et al., 1999).

A possibilidade de exploração e de uso das diferenças genotípicas em sorgo para a eficiência a fósforo se apresentam como uma das estratégias viáveis para contornar o problema da falta desse elemento nas regiões tropicais e subtropicais, conseqüência dos teores naturalmente baixos e da alta capacidade de fixação nos solos dessas áreas, tornando-o pouco disponível para as plantas.

$\mathrm{Na}$ planta, o fósforo, na forma de fosfato, pode constituir desde moléculas simples a mais complexas, sendo componente chave em moléculas, como ácido fítico, coenzimas, açúcares-fosfato, nucleotídeos, ácidos nucléicos e fosfolipídios. Na sua forma inorgânica, está envolvido no transporte de elétrons, no controle de reações enzimáticas e na regulação de vias metabólicas (Cantão, 2007).

Plantas eficientes na aquisição de fósforo $(\mathrm{P})$ têm sido definidas como aquelas que acumulam maiores concentrações desse nutriente em sua parte aérea e raízes, mesmo quando cultivadas em condições limitantes desse nutriente (Clarck \& Brown, 1974). Já para Fox (1978), plantas eficientes são aquelas que produzem grande quantidade de massa seca por unidade de nutriente ou tempo e área, desenvolvendo-se em meio que tenha $\mathrm{P}$ disponível menos do que suficiente para a máxima produtividade. No entanto, estudos de eficiência na utilização de $\mathrm{P}$ somente têm significado quando são comparadas plantas sob mesmas condições, quanto ao conteúdo de P disponível.

Entre as características correlacionadas com a eficiência no uso de $\mathrm{P}$, estão $\mathrm{o}$ comprimento total das plântulas e de suas partes (aérea e raiz). Essas características são relacionadas com a capacidade do genótipo em adaptar-se ao estresse por $\mathrm{P}$, emitindo raízes mais finas e profundas, ou reduzindo a produção de massa seca da parte aérea pela redistribuição de carboidratos (Cantão, 2007). Tecnicamente, outras características são associadas ao comprimento total, como o acúmulo de massa fresca e seca nas plântulas, relação de comprimento entre parte aérea e raiz, eficiência de produção de massa seca e velocidade de crescimento radicular (Camacho et al., 2002).

A determinação da variabilidade genética, com o uso da análise multivariada, em que diversas características avaliadas podem ser dimensionadas simultaneamente nos genótipos, apresenta-se bastante vantajosa. E podem ser úteis para identificar fontes de variabilidade genética, quantificar a importância de cada característica em relação à variabilidade genética e indicar a dose de 
P mais adequada para estudos genéticos, além de permitir aos melhoristas antever as combinações com maiores chances de sucesso, antes mesmo da realização das hibridações.

Dessa forma, o desenvolvimento de genótipos de sorgo adaptados às condições adversas de fertilidade do solo, notadamente à deficiência de fósforo, a introdução de material selecionado para determinados ambientes e o uso desses cultivares são aspectos interessantes do ponto de vista da eficácia no uso do adubo fosfatado e da sustentabilidade do sistema produtivo.

O presente trabalho teve como objetivos identificar a presença de diversidade genética entre acessos de sorgo cultivados em diferentes condições de disponibilidade de fósforo e determinar as características apropriadas para este estudo.

\section{Material e Métodos}

O experimento foi conduzido no município de Viçosa-MG, situado a $649 \mathrm{~m}$ de altitude, $20^{\circ} 45^{\prime} \mathrm{S}$ e $42^{\circ} 54^{\prime} \mathrm{W}$, em casade-vegetação pertencente ao departamento de Fitotecnia da Universidade Federal de Viçosa, nos meses de junho e julho de 2008. As temperaturas máxima e mínima no interior da casa-de-vegetação, durante o período de avaliação, foram de 36,5 e $9,5^{\circ} \mathrm{C}$, respectivamente. A umidade relativa oscilou entre 52 e $78 \%$. Os acessos avaliados foram os híbridos comerciais BR 601, BR 304, BRS 655, BRS 610, BR 700 e os híbridos experimentais 9920044, 0144013, 9920045 e 0735019, oriundos do programa de melhoramento de sorgo da Embrapa Milho e Sorgo (Tabela 1).

TABELA 1. Descrição dos híbridos de sorgo utilizados.

\begin{tabular}{ccc}
\hline Híbridos & Cultivar & Categoria Comercial \\
\hline H1 & 9920044 & Granífero \\
H2 & BRS 601 & Forrageiro \\
H3 & 0144013 & Granífero \\
H4 & BR 304 & Granífero \\
H5 & BRS 655 & Forrageiro \\
H6 & 9920045 & Granífero \\
H7 & 0735019 & Forrageiro \\
H8 & BRS 610 & Forrageiro \\
H9 & BR 700 & Forrageiro \\
\hline
\end{tabular}


O delineamento experimental utilizado foi em blocos casualizados, em esquema fatorial $9 \times 4$, constituído de nove híbridos (Tabela 1) e quatro doses de P (3, 32, 97 e 129 $\mu \mathrm{M}$ de $\mathrm{P} \mathrm{L}^{-1}$ de solução), com três repetições.

As sementes foram previamente desinfetadas em hipoclorito de sódio a 5\%, por cinco minutos, efetuando-se, posteriormente, cinco lavagens sucessivas em água destilada. Na seqüência, foram acondicionadas em rolos de papel germiteste, para germinar (Andrade Junior et al., 2005), em câmara de germinação tipo BOD, sob temperatura controlada $(25 \pm$ $\left.1^{\circ} \mathrm{C}\right)$.

Oito dias após a germinação, as plântulas com comprimento de raiz seminal entre 10 e $20 \mathrm{~cm}$, foram transferidas para solução nutritiva, como descrito por Furlani \& Furlani (1988). A composição da solução nutritiva foi, em $\mathrm{mg} \mathrm{L}^{-1}: \mathrm{Ca}=151 ; \mathrm{K}=141 ; \mathrm{Mg}=$ $17 ; \mathrm{N}^{-\mathrm{NO}_{3}}=138 ; \mathrm{N}^{-\mathrm{NH}_{4}}=20 ; \mathrm{S}=56 ; \mathrm{Cl}=$ $33 ; \mathrm{Fe}=3,6 ; \mathrm{Mn}=0,5 ; \mathrm{B}=0,27 ; \mathrm{Zn}=0,15$; $\mathrm{Cu}=0,04 ; \mathrm{Mo}=0,08$, nas formas de: $\mathrm{Ca}$ $\left(\mathrm{NO}_{3}\right)_{2} \cdot 4 \mathrm{H}_{2} \mathrm{O} ; \mathrm{NH}_{4} \mathrm{NO}_{3} ; \mathrm{KCl} ; \mathrm{K}_{2} \mathrm{SO}_{4} ; \mathrm{KNO}_{3}$; $\mathrm{MgSO}_{4} \cdot 7 \mathrm{H}_{2} \mathrm{O}$; Fe-HEDTA (preparado com HEDTA e FeSO $.7 \mathrm{H}_{2} \mathrm{O}$ ); $\mathrm{MnCl}_{2} \cdot 4 \mathrm{H}_{2} \mathrm{O} ; \mathrm{H}_{3} \mathrm{BO}_{3}$; $\mathrm{ZnSO}_{4} .7 \mathrm{H}_{2} \mathrm{O} ; \mathrm{CuSO}_{4} .5 \mathrm{H}_{2} \mathrm{O}$ e $\mathrm{Na}_{2} \mathrm{MoO}_{4} \cdot 2 \mathrm{H}_{2} \mathrm{O}$, respectivamente. $\mathrm{O} \mathrm{pH}$ inicial da solução foi 5,5, sendo esta continuamente arejada durante o experimento, não sendo renovada. $\mathrm{O}$ volume do vaso foi completado com água destilada em dias alternados e o $\mathrm{pH}$ foi ajustado para
5,5, usando-se $\mathrm{HCl}$ e $\mathrm{NaOH}$ a 0,1N (Furlani \& Furlani 1988; Machado et al., 2001). O suprimento de fósforo na solução obedeceu às seguintes doses: Alto P $\left(129 \mu \mathrm{M} \mathrm{L}^{-1}\right)$, Médio P (97 $\left.\mu \mathrm{M} \mathrm{L}^{-1}\right)$, Baixo $\mathrm{P}\left(32 \mu \mathrm{M} \mathrm{L}^{-1}\right)$ e muito baixo $\mathrm{P}\left(3 \mu \mathrm{M} \mathrm{L}^{-1}\right)$ (Furlani \& Furlani 1988; Machado et al., 2001; Machado \& Furlani, 2004).

Após o período de 25 dias, as plântulas foram individualmente colhidas, das quais foram obtidas as seguintes informações: comprimento inicial de raiz (CRI), tomado imediatamente antes do cultivo em solução nutritiva; comprimento da raiz seminal de cada plântula aos 2, 5, 10, 15, 20 e 25 dias em solução nutritiva, sendo este último considerado como comprimento de raiz final (CRF) e altura de plântula (ALT), obtida no momento de colheita; número de raízes adventícias (NRA); massa fresca de parte aérea (MFP); massa fresca de raiz (MFR); massa fresca total (MFT), obtidas no momento da colheita em balança de precisão com três casas decimais após a unidade grama $(\mathrm{g})$; massa seca de parte aérea (MSP); massa seca da raiz (MSR) e massa seca total (MST), obtida após secagem em estufa de ar forçado, por 48 horas, a $72^{\circ} \mathrm{C}$. Esses valores foram utilizados posteriormente para calcular o crescimento líquido diário médio de raiz (CLDRm) e o crescimento relativo de raiz seminal (CRRS). O CLDRm foi obtido pela fórmula: 


$$
C L D R m=\left[\sum_{i=1}^{6}\left(C R T_{i}-C R T_{i-1}\right)\right] / 6
$$

Em que: $\mathrm{CRT}_{\mathrm{i}}$ é o comprimento de raiz no tempo i e $\mathrm{CRT}_{\mathrm{i}-1}$ é o comprimento de raiz medido anteriormente ao tempo i. Já o crescimento relativo de raiz seminal (CRRS) foi obtido pela fórmula:

$$
C R R S=100 .(C R F-C R I) / C R I
$$

A velocidade de crescimento radicular (VCR) foi dada pela fórmula:

$$
V C R=(C R F-C R I) / 25
$$

A velocidade de emergência (VE), dada pelo CRI dividido pelo número de dias para a germinação (oito dias); a relação entre parte aérea e raiz (PA/RA) foi calculada pela razão entre a altura da plântula e o comprimento de raiz final.

As análises genético-estatísticas foram realizadas utilizando-se o programa GENES (Cruz, 2007). Foi utilizado o teste de ScottKnott em nível de significância de 5\% de probabilidade, visando agrupar as médias dos genótipos entre e dentro de cada dose de P.

As análises multivariadas foram empregadas para avaliar a variabilidade genética entre os acessos, aplicando-se técnicas de agrupamento. Para isso, utilizou-se a distância generalizada de Mahalanobis como medida de dissimilaridade e, para agrupamento dos genótipos, o método de otimização de Tocher, adotando-se o critério de que a média das medidas de divergência dentro de cada grupo deve ser menor que as distâncias médias entre quaisquer grupos. Estudou-se, ainda, a importância relativa das diversas características para a divergência genética, baseando-se na metodologia de Singh (1981), conforme descrito por Cruz \& Regazzi (2006).

\section{Resultados e Discussão}

Ao tentar realizar a análise de variância conjunta para os genótipos dentro dos quatro níveis de $\mathrm{P}$, verificou-se a falta de homogeneidade das variâncias para a maior parte das características, devido à presença da dose de $3 \mu \mathrm{M} \mathrm{L}^{-1}$ de P na solução nutritiva, que demonstrou ser bem discrepante dos demais.

Com a retirada da dose mais baixa de $\mathrm{P}$ em solução $\left(3 \mu \mathrm{M} \mathrm{L}^{-1}\right)$, procedeu-se à análise conjunta dos demais níveis $\left(36,97\right.$ e $129 \mu \mathrm{ML}^{-1}$ de $\mathrm{P}$ ), por meio do teste $\mathrm{F}$, com o qual se pode evidenciar que há diferenças entre os genótipos ao nível de $1 \%$ de probabilidade, para todas as características avaliadas. Concomitantemente, observa-se diferença entre os ambientes para 10 das 15 características, sendo que, para as características crescimento radicular inicial e velocidade de emergência, já era esperado o resultado observado, pois essas foram avaliadas anteriormente ao cultivo em solução nutritiva, não devendo demonstrar diferenças entre os níveis de fósforo avaliados. 


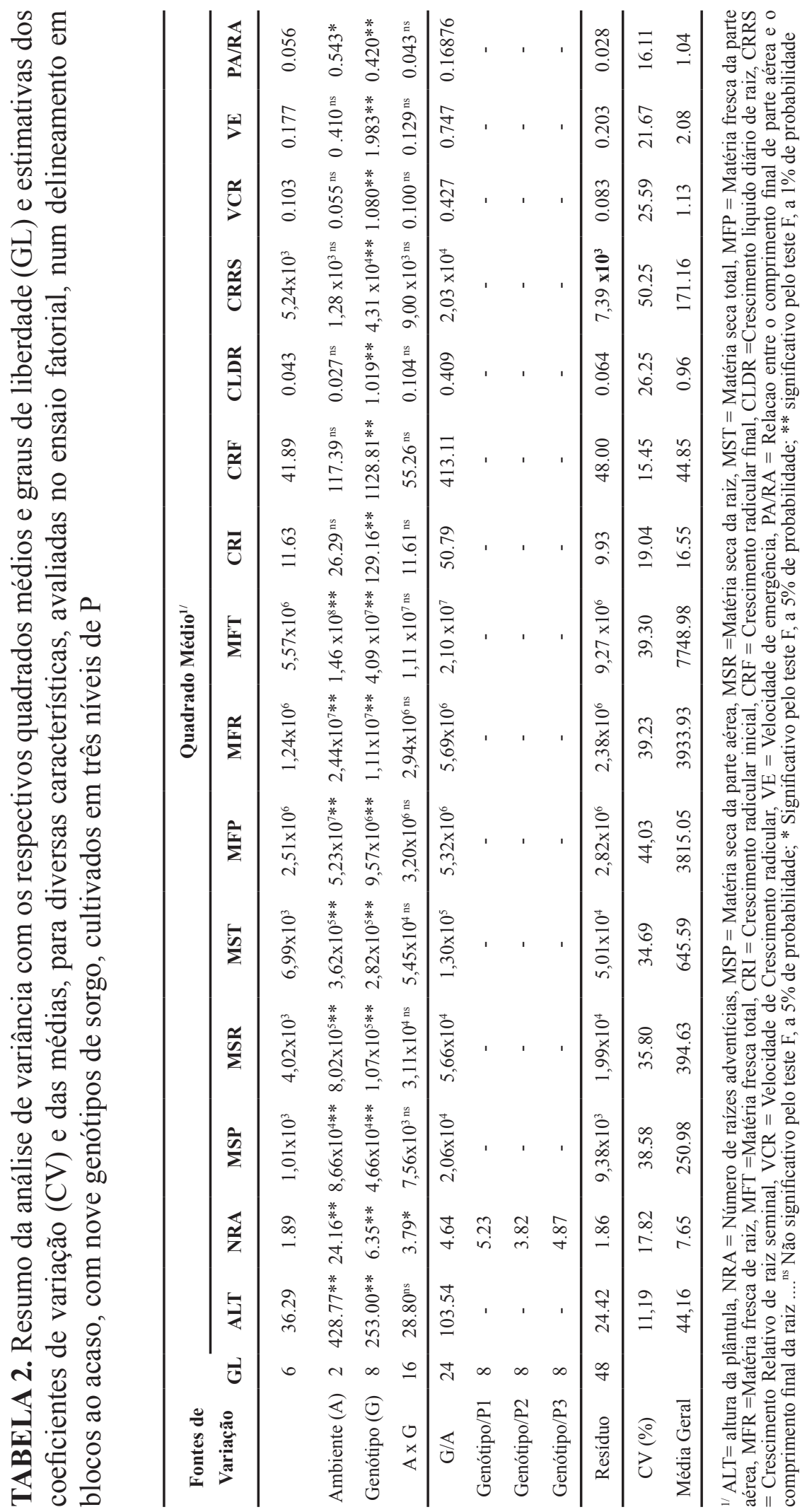




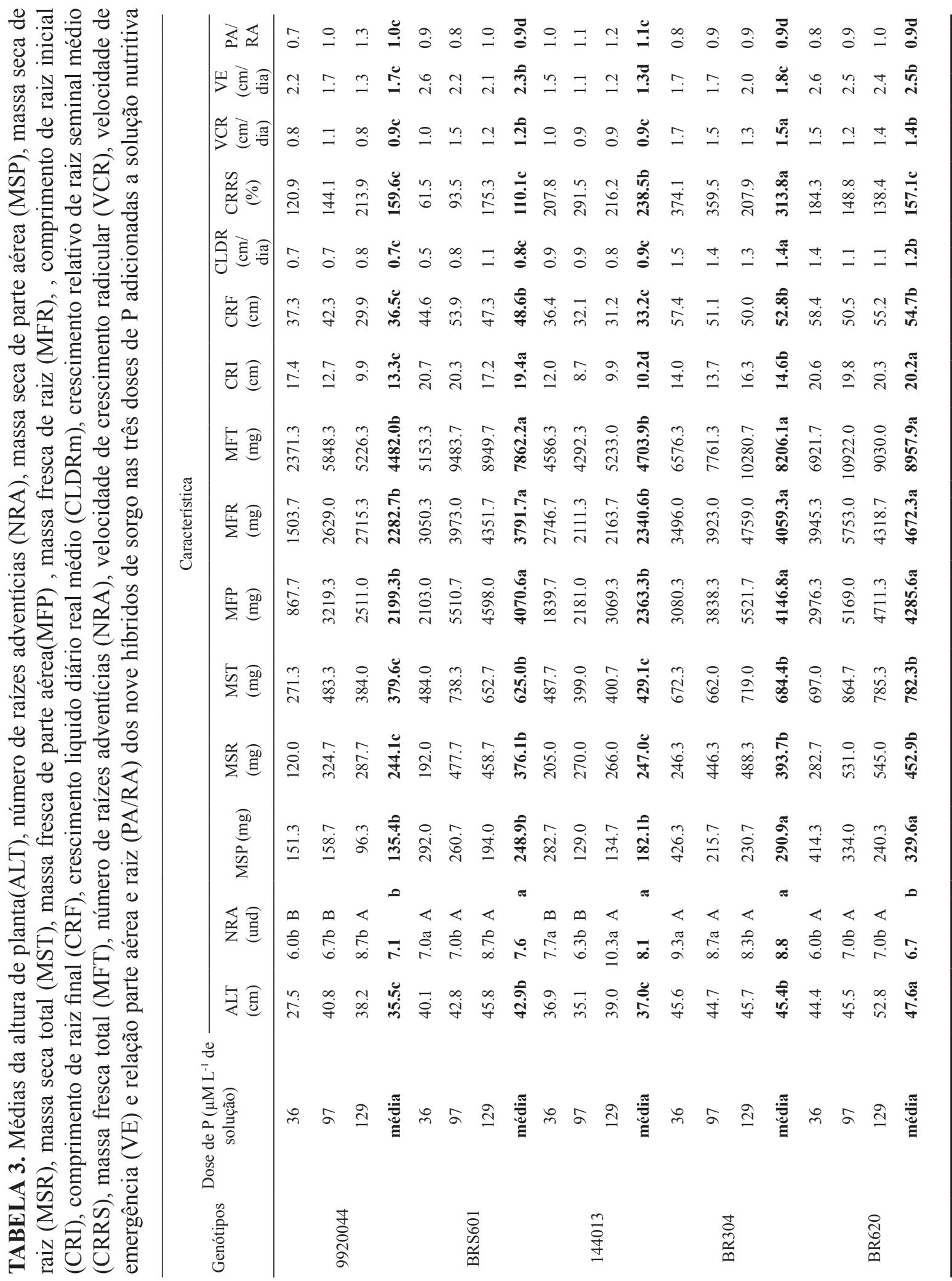




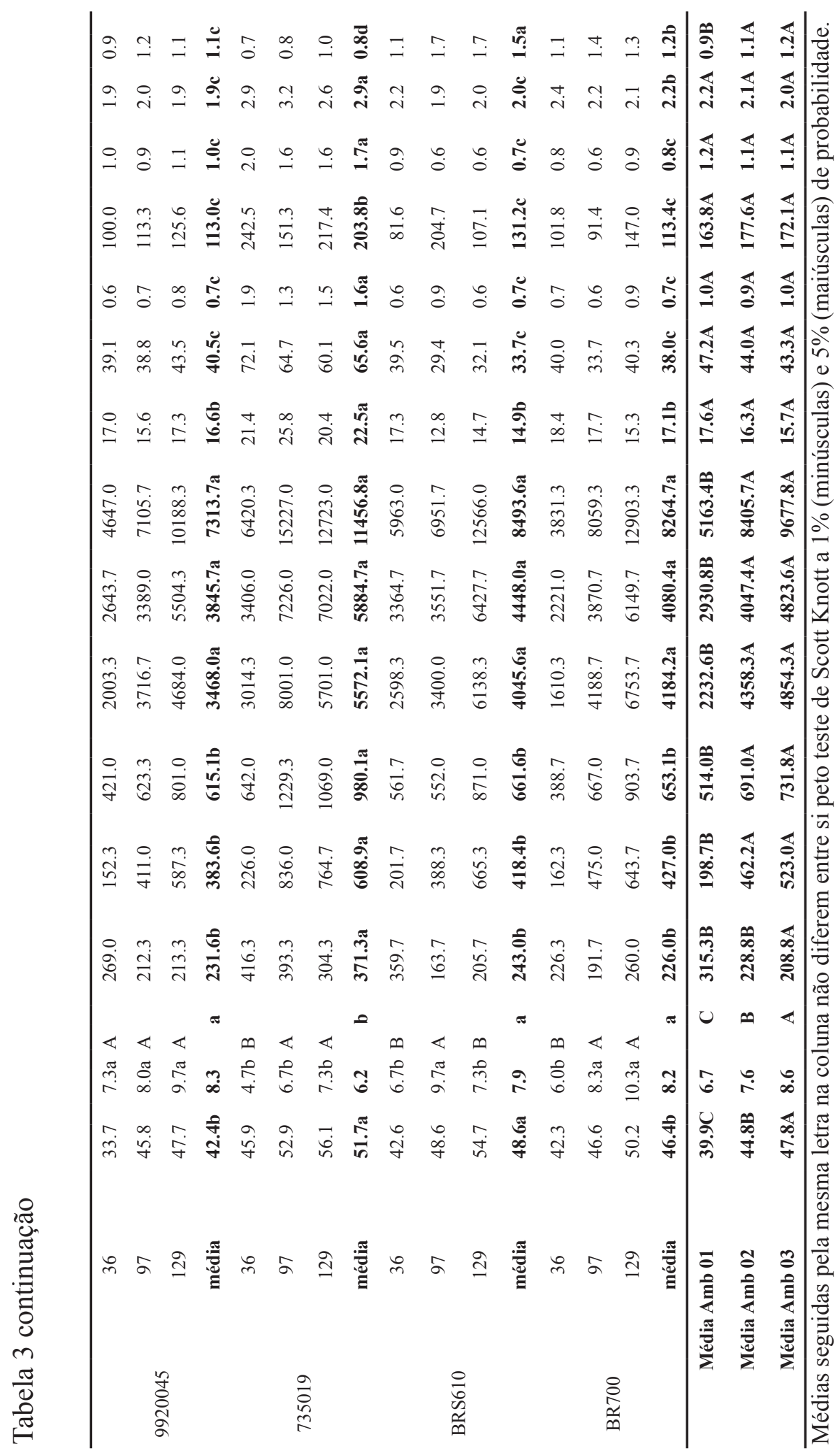


Pode-se, ainda, observar que, para 14 das 15 características avaliadas, não se verificou interação genótipo e ambiente (Tabela 2); a exceção foi a característica número de raízes adventícias (NRA), sendo este crescente com o aumento nas doses de P. Resultados semelhantes foram encontrados por Bressan et al. (2002), estudando alterações morfológicas no sistema radicular do milho induzidas por fungos micorrízicos e fósforo.

Considerando as médias das 15 características avaliadas (Tabelas 3 e 4), por meio da análise multivariada, constatou-se divergência genética onde pelo menos uma característica foi diferente entre os híbridos, em todos os níveis de $\mathrm{P}$ adicionadas à solução (Tabela 4). De modo geral, os híbridos H4(BR304) e H8(BRS610) permaneceram individualmente em grupos distintos, não estando correlacionados com outros, em diferentes níveis de $\mathrm{P}$ em solução, indicando que eles são os mais divergentes dentro deste estudo. Observou-se, também, que os híbridos H5 (BRS 655) e H7 (0735019) mantiveramse agrupados, independentemente da dose de P em solução. Essa correlação é explicada pela proximidade genética entre esses híbridos, uma vez que se originaram de uma mesma fêmea cruzada com diferentes machos. Os demais híbridos comportaram-se de modo variado, de acordo com a dose de $\mathrm{P}$, não sendo observada relação entre o tipo de material (forrageiro e granífero) e os resultados obtidos. Isso é evidenciado quando se observa o resultado da análise conjunta dos dados, na qual os genótipos comportam-se de acordo com a divergência genética observada.

Dentre os níveis de $\mathrm{P}$ avaliados, o de $97 \mu \mathrm{M} \mathrm{L}^{-1}$ de $\mathrm{P}$ gerou maior expressão da variabilidade genética entre os híbridos,

TABELA 4. Agrupamento dos nove híbridos de sorgo $(\mathrm{H})$, pelo método de Tocher, considerando as 20 características analisadas, nas quatro doses de $\mathrm{P}$ adicionadas à solução nutritiva.

\begin{tabular}{rccccc}
\hline \multirow{2}{*}{ Grupos } & \multicolumn{5}{c}{ Dose de $\mathbf{P}\left(\boldsymbol{\mu} \mathbf{M ~ L}^{-1}\right.$ de solução $)$} \\
\cline { 2 - 6 } & $\mathbf{1}$ & 298631 & 16293 & 24579613 & 69213 \\
\hline \multirow{2}{*}{ Sub- } & $\mathbf{1 . 1}$ & 298 & 162 & 24 & 69 \\
& $\mathbf{1 . 2}$ & 36 & 9 & 13 & 13 \\
grupos & $\mathbf{1 . 3}$ & 1 & 3 & 69 & 2 \\
& $\mathbf{1 . 4}$ & & & 57 & 57 \\
\hline $\mathbf{2}$ & & 57 & 57 & 8 & 4 \\
$\mathbf{3}$ & 4 & 4 & & 8 \\
\hline
\end{tabular}


levando-se em consideração a formação de quatro grupos distintos, enquanto as demais doses resultaram na formação de três $(33 \mu \mathrm{M}$ $\mathrm{L}^{-1}$ de $\left.\mathrm{P}\right)$ e dois (129 $\mu \mathrm{M} \mathrm{L}^{-1}$ de $\left.\mathrm{P}\right)$ grupos (Tabela 04). Segundo Cruz \& Regazzi (2006), a formação desses grupos representa a minimização da variabilidade genética dentro deles e maximização da variabilidade genética entre os mesmos, sendo esses dados de suma importância para programas de melhoramento, como descrito por Cantão (2007).

A dose de $129 \mu \mathrm{M}_{\text {de }} \mathrm{P} \mathrm{L}^{-1}$ é tida por vários autores como a ideal para trabalhos com milho em solução nutritiva, (Machado et al., 2001; Alves et al., 2002, Machado \& Furlani, 2004), representando o valor ótimo para a produção dessa cultura em solução nutritiva, conforme descrito por Machado \& Furlani (2004). Já a dose de $97 \mu \mathrm{M}$ de $\mathrm{P} \mathrm{L}^{-1}$ encontrase intermediariamente entre a dose ótima (129 $\mu \mathrm{M}$ de $\mathrm{P} \mathrm{L}^{-1}$, tida como ótimo) e a dose crítica (65 $\mu \mathrm{M}$ de $\left.\mathrm{P} \mathrm{L}^{-1}\right)$, ou seja, a dose a partir do qual as plantas começam a apresentar sintomas de deficiência, como redução da matéria seca total, redução da relação parte aérea e raiz, similarmente ao observado por Machado et al. (2001), na cultura do milho.

Logo, a dose de $97 \mu \mathrm{M}$ de $\mathrm{P} \mathrm{L}^{-1}$ tornase interessante para futuros trabalhos na aérea, já que poderá aumentar a acurácia dos dados observados nos dois níveis contrastantes e a sensibilidade do experimento, uma vez que, nessa dose, os genótipos, de modo geral, apresentaram comportamento diferente da dose mais alto de $\mathrm{P}$, aproximando seu resultado aos obtidos na dose mais baixa de $\mathrm{P}$, mesmo não apresentando sinais visuais, como presença de antocianina nas folhas, de estresse por fósforo. Por não representar uma situação de estresse por déficit de fósforo, recomenda-se o uso de uma dose menor de fósforo em solução, como a de $36 \mu \mathrm{M}$ de $\mathrm{P} \mathrm{L}^{-1}$. Níveis inferiores a $36 \mu \mathrm{M}$ $\mathrm{L}^{-1}$ de $\mathrm{P}$ apresentam problemas para a execução do experimento, como relatado inicialmente por Furlani et al. (1985) e observado ao longo deste experimento, através da perda de material, baixa homogeneidade dentro do mesmo genótipo e ausência de homogeneidade das variâncias geradas pelos valores discrepantes dos demais.

Entre as características analisadas, a matéria seca total apresentou a maior contribuição para divergência genética $(38,67 \%$, em média), nos três níveis avaliados (Tabela 5). Para este estudo, as características não relacionadas com o crescimento da plântula, em diferentes níveis de fósforo, foram desconsideradas, tendo em vista recomendação de Cruz \& Regazzi (2006), por se tratarem de dados redundantes.

Em contrapartida, observa-se, na Tabela 5, que, para a dose alta de $\mathrm{P}\left(129 \mu \mathrm{M}\right.$ de $\left.\mathrm{P} \mathrm{L}^{-1}\right)$ em solução altera-se a importância relativa de cada característica, sendo a matéria seca de raiz a característica de maior importância, haja vista o amplo crescimento das raízes nessa dose, o que é confirmado quando se observam os dados obtidos por Camacho et al. (2002), que, 
TABELA 5. Contribuição relativa das características para a divergência (S.j) e em porcentagem (\%), de acordo com a metodologia proposta por Singh (1981), das seguintes características: altura de plântula (ALT); número de raízes adventícias (NRA); matéria seca da parte aérea (MSP); matéria seca de raiz (MSR), matéria seca total (MST), crescimento radicular final (CRF); crescimento líquido diário de raiz (CLDR); crescimento relativo de raiz seminal (CRRS); velocidade de crescimento radicular (VCR); relação comprimento de parte aérea e comprimento final de raiz (PA/ CA), nas três doses de $\mathrm{P}$ adicionadas a solução nutritiva, utilizadas para a análise de divergência, assim como na análise conjunta dos três níveis.

\begin{tabular}{|c|c|c|c|c|c|c|c|c|}
\hline \multirow{3}{*}{$\begin{array}{l}\text { Caracte- } \\
\text { rística }\end{array}$} & \multicolumn{6}{|c|}{ Dose de $\mathrm{P}\left(\mu \mathrm{M}\right.$ de P.L $^{-1}$ de solução $)$} & & \\
\hline & \multicolumn{2}{|c|}{36} & \multicolumn{2}{|c|}{97} & \multicolumn{2}{|c|}{129} & \multicolumn{2}{|c|}{ Conjunta } \\
\hline & S.j & $\%$ & S.j & $\%$ & S.j & $\%$ & S.j & $\%$ \\
\hline ALT & 62.09 & 0.20 & $12 \cdot 05$ & $0 \cdot 04$ & $150 \cdot 64$ & $2 \cdot 67$ & $54 \cdot 49$ & 0.21 \\
\hline NRA & $97 \cdot 46$ & 0,32 & $50 \cdot 40$ & $0 \cdot 17$ & 95.62 & 1.69 & 39.68 & 0.15 \\
\hline MSP & $10952 \cdot 03$ & 35,99 & $8155 \cdot 40$ & $28 \cdot 17$ & 1176,73 & 2084 & 6605,58 & 24.93 \\
\hline MSR & $3849 \cdot 06$ & $12 \cdot 65$ & 5918,55 & $20 \cdot 45$ & 2214.65 & $39 \cdot 22$ & $6291 \cdot 14$ & 23,74 \\
\hline MST & 14608,73 & $48 \cdot 00$ & $13969 \cdot 54$ & $48 \cdot 26$ & $1124 \cdot 17$ & $19 \cdot 91$ & 12861,91 & 48,54 \\
\hline CRF & 433.03 & 1.42 & 1,47 & $0 \cdot 01$ & 121,03 & $2 \cdot 14$ & $104 \cdot 60$ & 0.39 \\
\hline CLDR & 333,96 & $1 \cdot 10$ & 56.64 & 0.20 & $96 \cdot 31$ & 1.71 & 119.06 & 0.45 \\
\hline CRRS & 15,69 & 0.05 & 107.39 & $0 \cdot 37$ & 0.32 & $0 \cdot 01$ & 33.07 & 0.12 \\
\hline VCR & 38,98 & 0.13 & $90 \cdot 08$ & 0.31 & $102 \cdot 15$ & 1,81 & $103 \cdot 67$ & 0.39 \\
\hline $\mathbf{P A} / \mathbf{C A}$ & 42.81 & $0 \cdot 14$ & 585,42 & $2 \cdot 02$ & 564.40 & $10 \cdot 00$ & 283,97 & 1,07 \\
\hline
\end{tabular}

trabalhando com sorgo granífero, relataram o peso de matéria seca de raiz como uma das principais característica correlacionadas com a eficiência no uso de P.

Outros trabalhos relatam a relação encontrada entre produção de matéria seca total e eficiência no uso de fósforo (Moura et al., 1999; Machado et al., 2001; Camacho et al., 2002; Machado \& Furlani, 2004; Prado \& Vidal, 2008). No caso dos genótipos avaliados para essa característica, pode-se observar um destaque do híbrido forrageiro experimental 0735019 (H7), que obteve a maior média nessa característica, em todos os níveis de fósforo 
(Tabela 2), sendo considerado um genótipo eficiente no uso do fósforo para produção de matéria seca. Em contrapartida, observouse que os híbridos graníferos 9920044 (H1) e 0144013 (H3) obtiveram médias inferiores aos demais em todos os níveis de fósforo, sendo considerados para esse caractere como genótipo não eficiente. Os demais genótipos comportaram-se de modo aleatório ao longo dos níveis de fósforo em solução.

Paralelamente ao aumento da produção de matéria seca total, observa-se, na Tabela 2, que os ganhos obtidos de matéria seca foram mais pronunciados no sistema radicular do que na parte aérea. Esses resultados assemelhamse aos obtidos por Brasil (2003) e Cantão (2007). De acordo com esses autores, vários estudos têm demonstrado essa tendência de maior incremento da matéria seca do sistema radicular em detrimento do incremento da matéria seca da parte aérea, para diversas espécies, sob condições de deficiência de P.

Segundo Cantão (2007), quando alguns nutrientes limitam o crescimento das plantas, principalmente $\mathrm{PeN}$, as raízes tornam-se drenos relativamente mais fortes para carboidratos, em relação à parte aérea, ocorrendo, com isso, redução desta antes que as raízes sejam afetadas. A redução do crescimento da parte aérea em condições de deficiência de $\mathrm{P}$ também pode estar relacionada com o decréscimo da produção de citocinina nas raízes e a redução da translocação desta para a parte aérea. A citocinina está envolvida na senescência das folhas e, de forma indireta, no fechamento dos estômatos.

Esses resultados vêm a reforçar a hipótese de que os efeitos primários decorrentes da deficiência de $\mathrm{P}$ em plantas estão relacionados às características da raiz, que incluem modificações na arquitetura radicular (Nielsen et al., 1998; Hinsiger, 2001; Lynch \& Brown, 2001).

As características comprimento de raiz final (CRF) e relação entre altura da planta e comprimento final de raiz (PA/RA) apresentaram diferenças significativas entre os genótipos submetidos aos diferentes níveis de P. No entanto, não houve interação genótipo e ambiente para essas características (Tabela 3). Camacho et al. (2002) verificaram que a característica relação massa seca de parte aérea e massa seca de raiz foi a que mais contribuiu para a expressão da variabilidade genética entre progênies de sorgo granífero.

Em geral, os híbridos H1 (9920044), H3 (0144013)e H7 (0735010) apresentaram comportamento semelhante e, de modo geral, apresentaram também as maiores médias de comprimento final de raiz, ao contrário dos demais genótipos, os quais apresentaram comportamento aleatório (Tabela 2). Esses resultados seriam um indício de que esses híbridos são mais eficientes na aquisição de 
nutrientes, pois, como descrito por Cantão (2007), Bressan et al. (2002) e Schachtman et al. (1998), plantas com maior sistema radicular teriam maior capacidade de absorver nutrientes pouco móveis no solo, como é o caso do P. Para esses autores, o comprimento da raiz final é uma das principais características de sistema radicular responsáveis pela eficiência na utilização de $\mathrm{P}$, e isto é reforçado por Horst et al. (2001), quando esses autores, trabalhando com solos, evidenciaram que o fósforo apresenta baixa mobilidade no solo, sendo transportado via difusão, o que ressalta a importância da exploração do solo pelo sistema radicular.

O aumento do sistema radicular em resposta à baixa disponibilidade de $\mathrm{P}$ tem sido observado, freqüentemente, para várias espécies vegetais (Moura et al., 1999; Machado et al., 2001, Camacho et al., 2002; Cantão, 2007), o que caracteriza a hipótese de que as raízes são drenos preferenciais de fotoassimilados quando alguns nutrientes são fatores limitantes para o crescimento das plantas, principalmente P e N. Segundo Horst et al. (2001) e Cantão (2007), essa pode ser uma estratégia de adaptação desenvolvida para aumentar a eficiência de absorção quando há limitação desses nutrientes.

Parentoni et al. (1999), trabalhando com acessos de milho contrastantes para eficiência de uso de $\mathrm{P}$, concluiu que genótipos ineficientes na utilização de $\mathrm{P}$, quando cultivados em solução nutritiva, com omissão desse elemento, não apresentaram diferenças quanto à morfologia do sistema radicular, enquanto que os eficientes aumentaram a massa e o comprimento de raízes, em baixa disponibilidade de $\mathrm{P}$. Baseando-se nessas características, podese destacar o híbrido experimental 0735019 como o genótipo mais eficiente para o uso do fósforo, uma vez que esse híbrido apresentou médias superiores em todos os tratamentos, para todas as características correlacionadas com a eficiência no uso de P. Outro ponto interessante é o comportamento contraditório dos híbridos 9920044 e 0144013, que, a princípio, foram colocados como genótipos pouco eficientes, quando só se considerava a matéria seca total. Porém, quando analisados pelas medidas de crescimento do sistema radicular, esses genótipos comportaram-se como genótipos eficientes. Esse fato reforça que o estudo de divergência genética deve se basear em várias características, uma vez que a observação de um número reduzido de características pode promover o descarte de materiais geneticamente superiores dentro de um programa de seleção.

Observa-se, ainda, que as características crescimento relativo de raiz seminal, altura e crescimento líquido diário médio foram, em ordem decrescente, as que apresentaram as menores contribuições para a expressão da variabilidade genética. Essa situação leva 
à reflexão sobre a relevância de algumas características para estudos de diversidade genética, que pode ser alta em uma situação e baixa em outra, cabendo ao pesquisador buscar características de fácil observação e elevada relevância para o estudo pretendido.

\section{Conclusões}

1. A análise multivariada é efetiva para detectar variabilidade genética quanto à eficiência nutricional relacionada à utilização de $\mathrm{P}$, a dose desse nutriente mais apropriada para estudos genéticos, como também para identificar o caráter que mais contribui para essa variabilidade.

2. O nível de $97 \mu \mathrm{M}$ de $\mathrm{P}$ L-1 de solução foi o que gerou o maior número de grupos entre os genótipos avaliados, porém, essa concentração não caracteriza estresse por $\mathrm{P}$, sendo recomendada, para estudos de variabilidade de genótipos sobre estresse de $\mathrm{P}$, o uso de níveis inferiores a esses como, por exemplo, $36 \mu \mathrm{M}$ de P L-1.

3. As características mais importantes nas doses de $\mathrm{P}$ avaliadas para determinação de diversidade genética estão relacionadas com a morfologia do sistema radicular, sendo elas: produção de matéria seca total e comprimento final de raiz.
4. Sugere-se verificar, em futuras pesquisas, a possível correlação entre características relacionadas com morfologia de raiz e aquelas associadas à produção de grãos ou silagem, o que viabilizaria a utilização da mesma para seleção precoce de genótipos para ambientes com baixos teores de P.

\section{Literatura Citada}

ALVES, V. M. C.; PARENTONI, S. N.; VASCONCELLOS, C. A.; PITTA, G. V. E.; FRANÇA, C .C. M. Cinética de absorção de fósforo e crescimento do sistema radicular de genótipos de milho contrastantes para eficiência a fósforo. Revista Brasileira de Milho e Sorgo, Sete Lagoas, v. 1, n. 1, p .8592, 2002.

ANDRADE JÚNIOR, V. C.; MOTA, J. H.; CASTRO, N. E. A. Avaliação da tolerância a alumínio de dois genótipos de sorgo. Revista Científica Eletrônica de Agronomia, Garça, v. 4, n. 7, p. 1-9, 2005.

BOUTRAA, T. Growth and carbon partitioning of two genotypes of bean (Phaseolus vulgaris) grown with low phosphorus availability. EurAsian Journal of BioSciences, Konak, v. 3, p. 17-24, 2009.

BRASIL, E. C. Mecanismos envolvidos na eficência de aquisição de fósforo em genótipos de milho. 2003. 161 f. Tese (Doutorado) - Universidade Federal de Lavras, Lavras. 
BRASIL, E. C.; ALVES, V. M. C.; MARRIEL, I. E., PITTA, G. V. E.; CARVALHO, J. G. Matéria seca e acúmulo de nutrientes em genótipos de milho contrastantes quanto a aquisição de fósforo. Revista Ciência Agrotecnologia, Lavras, v. 31, n. 3, p. 704712, 2007.

BRESSAN, W.; VASCONCELLOS, C. A. Alterações morfológicas no sistema radicular do milho induzidas por fungos micorrízicos e fósforo. Pesquisa Agropecuária Brasileira, Brasília, DF, v. 37, n. 4, p. 509-517, 2002.

CAMACHO, R.; MALAVOLTA, E.; GUERRERO-ALVES, J. et al. Vegetative growth of grain sorghum in response to phosphorus nutrition. Scientia Agricola, Piracicaba, v. 59, n. 4, p.771-776, 2002.

CANTÃO, F. R. O. Marcadores morfológicos de raiz em genótipos de milho contrastantes para tolerância à seca em resposta a estresses de fósforo e alumínio. 2007. 108 f. Monografia (Graduação) - Universidade Federal de Lavras, Lavras.

CLARK, R. B.; BROWN, J. C. Differential mineral uptake by maize inbrebs. Communications in Soil Science and Plant Analysis, New York, v. 5, p. 213-227, 1979.

CRUZ, C. D. Programa Genes - Versão Windows: aplicativo computacional em Genética e Estatística. Viçosa: Universidade Federal de Viçosa, 2007.

CRUZ, C. D.; REGAZZI, A. J. Modelos biométricos aplicados ao melhoramento genético. Viçosa: UFV, 2006. 585 p.
FOX, R. H. Selection for phosphorus efficiency in corn. Comunications in Soil Science and Plant Analysis, New York, v. 9, n. 1, p. 13-37, 1978.

FURLANI, A. M. C.; FURLANI, P. R. Composição e pH de soluções nutritivas para estudos fisiológicos e seleção de plantas em condições nutricionais adversas. Campinas: Instituto Agronômico, 1988. 34 p. (Instituto Agronômico. Boletim, 121).

FURLANI, A. M. C.; BATAGLIA, O. C.; LIMA, M. Eficiência de linhagens de milho na absorção e utilização de fósforo em solução nutritiva. Bragantia, Campinas, v. 44, n.1, p.129-147, 1985.

GABELMAN, W. H. Genetic potentials in nitrogen, phosphorus and potassium efficiencies. In: WORKSHOP ON PLANT ADAPTATION TO MINERAL STRESS IN PROBLEM SOILS, 1976, Beltsville. Plant adaptation to mineral stress in problem soils - proceedings. Beltsville: NAL, 1976. p. 205-212. Editado por Madison J. Wright, Sheila A. Ferrari.

GERLOFF, G. C. Plant efficiencies in the use of nitrogen, phosphorus and potassium. $\ln$ : WORKSHOP ON PLANT ADAPTATION TO MINERAL STRESS IN PROBLEM SOILS, 1976, Beltsville. Plant adaptation to mineral stress in problem soils - proceedings. Beltsville: NAL, 1976. p. 161-173. Editado por Madison J. Wright, Sheila A. Ferrari.

HINSINGER, P. How do plant roots acquire minerals nutrients? Chemical process involved in the rhizosphere. Advances in Agronomy, New York, v. 64, p. 225-265, 1998. 
HORST, W. J.; KAMH, M.; JIBRIN, J. M.; CHUDE, V. O. Agronomic measurements for increasing $\mathrm{P}$ availability to crops. Plant and Soil, Dordrecht, v. 237, n. 2, p. 211-233, 2001.

LYNCH, J. P.; BROWN, K. M. Topsoil foraging: an architectural adaptation to low phosphorus availability. Plant and Soil, Dordrecht, v. 237, n. 2, p. 225-237, 2001.

MACHADO, C. T. T.; GUERRA, J. G. M.; ALMEIDA, D. L.; MACHADO, A. T. Variabilidade entre genótipos de milho para eficiência no uso de fósforo. Bragantia, Campinas, v. 58, n. 1, p. 109-124, 1999.

MACHADO, C. T. T. ; FURLANI, A. M. C.; MACHADO, A. T._ Índices de eficiência de variedades locais e melhoradas de milho ao fósforo. Bragantia, Campinas, v. 60, n. 3, p. 225-238, 2001.

MACHADO, C. T. T.; FURLANI, A. M. C. Kinetics of phosphorus uptake and root morphology of local and improved varieties of maize. Scientia Agricola, Piracicaba, v. 61, p. 69-76, 2004.

MOURA, W. de M.; CASALI, V. W. D.; CRUZ, C. D. Genetic divergence of phosphorus nutritional efficiency in sweet pepper lines. Pesquisa Agropecuária Brasileira, Brasília, DF, v. 34, n. 2, p. 217-224, 1999.

NIELSEN, K. L.; MILLER, C. R.; BECK, D.; LYNCH, J. P. Fractal geometry of root system: Field observations of contrasting genotype of common bean (Phaseolus vulgaris L.) grown under different phophorus regimes. Plant and Soil, Dordrecht, v. 206, n. 2, p. 181-190, 1998.

PARENTONI, S. N.; GAMA, E.E. G.; SANTOS, M. X.; LOPES, et al. Adaptação de milho a solos ácidos: Tolerância à toxidez de alumínio e eficiência no uso de nutrientes no programa de pesquisa da EMBRAPA - Milho e Sorgo. In: REUNION LATINO AMERICANA DEL MAIZ, 18., 1999, Sete Lagoas. Memórias... Sete Lagoas: Embrapa Milho e Sorgo; México: CIMMYT, 1999. p. 179-199.

PRADO, R. M.; VIDAL, A.A. Efeitos da omissão de macronutrientes em solução nutritiva sobre o crescimento e a nutrição do milheto. Pesquisa Agropecuária Tropical, Goiânia, v. 38, n. 3, p. 208-214, 2008.

SCHACHTMAN, D. P.; REID, R. J.; AYLING, S. M. Phosphourus uptake by plants: from soil to cell. Plant Physiology, Rockville, v. 116, n. 2, p. 147-153, 1998.

SINGH, D. The relative importance of characters affecting genetic divergence. Indian Journal of Genetics and Plant Breeding, New York, v. 41, n. 2, p. 237- 245, 1981.

WHITEAKER， G.; GERLOFF， G. C.; GABELMAN, W. H.; LINDGREN, D. Intraspecific differences in growth of beans at stress levels of phosphorus. Journal American Society for Horticultural Science, Mount Vernon, v. 101, n. 4, p. 472-475, 1976. 
